\title{
Lutas Sociais e Direitos Humanos da criança e do adolescente: uma necessária articulação
}

\section{Social struggles and children and adolescents' Human Rights: a necessary articulation}

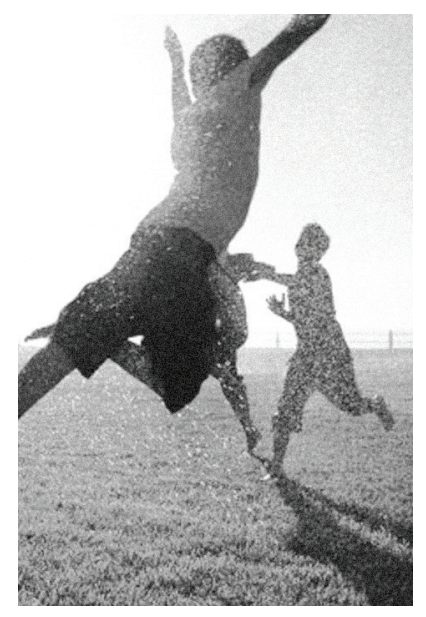

Aurea Satomi Fuziwara*

Resumo: Este artigo problematiza os direitos humanos da criança e do adolescente, com fundamento na teoria crítica, abordando a sua construção histórica e os processos políticos em que se inserem. Problematizando dados sobre a situação da infância, reflete criticamente sobre o uso do discurso em torno da defesa de direitos.

Palavras-chave: Direitos humanos. Criança e adolescente. Lutas sociais.

\begin{abstract}
In this article we discuss the children and the adolescents' human rights. The discussion is based on the Critical Theory, and it approaches their historical construction and political processes in which they operate. While it discusses data related to the situation of childhood, it critically debates about the use of discourse in the defense of rights.
\end{abstract}

Keywords: Human Rights. Child and adolescent. Social struggles.

* Assistente social, servidora do Tribunal de Justiça do Estado de São Paulo, docente em pós-graduação lato sensu, doutoranda no Programa de Estudos Pós-Graduados em Serviço Social da Faculdade de Ciências Sociais na Pontifícia Universidade Católica (PUC-SP), São Paulo, Brasil. pesquisadora do Núcleo de Pesquisa sobre Ética e Direitos Humanos (NEPEDH) do mesmo programa. E-mail: fuziwara.aurea@gmail.com. 


\section{Introdução}

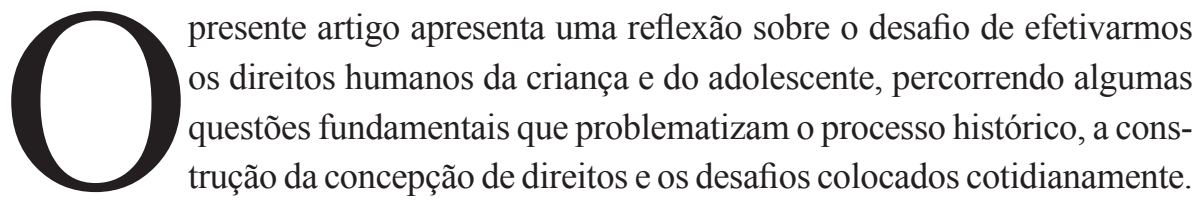

A literatura técnica e científica tem abordado os direitos da criança e do adolescente sob diferentes prismas, abordando seu desenvolvimento, suas demandas, seus direitos, as políticas sociais públicas e privadas, as campanhas de promoção e defesa de direitos etc. Ou seja, um grande volume de enfoques que fragmentam a realidade pode obscurecer aspectos cruciais para compreender e enfrentar a violação de direitos por ação e por omissão, seja da família, da sociedade e/ou do Estado.

\section{Ainfância na história}

Para problematizarmos a realidade vivida pelas crianças e adolescentes exige-se sempre um olhar histórico. Philippe Ariès é um historiador ao qual pesquisadores das mais diferentes perspectivas recorrem. É preciso salientar, em nossa perspectiva, que a retirada da densidade das lutas históricas e do enfoque dos seus protagonistas em geral propicia apenas uma descrição dos fenômenos, não possibilitando aprofundar as contradições existentes.

Consideramos ser determinante para esta análise partirmos da compreensão da construção dos direitos humanos no processo histórico, abarcando a infância nesse processo. Assim como muitos autores, utilizávamos do termo "a história da infância", mas atentando para esta expressão, atualmente a consideramos inapropriada. Afinal, não há uma história da infância, mas existem complexas expressões das ações humanas em relação à criança e ao adolescente no processo histórico. Esta é uma primeira demarcação que pode nos auxiliar numa leitura mais aprofundada sobre o tema. Com essa perspectiva, torna-se inerente refletir sobre as lutas sociais em que esse segmento se fez presente, em geral vitimizado pela negação da sua condição peculiar de pessoa em desenvolvimento. Não por acaso, o Estatuto da Criança e do Adolescente tem esse princípio que perpassa toda sua fundamentação. 
Ainda nos atendo à situação da infância, Ariès é um autor fundamental, que em sua análise traz elementos para o olhar atento ao cotidiano da sociedade, investigando as relações aparentemente triviais para a história. Este autor faz parte de um leque de pesquisadores que passam a se preocupar com essas relações buscando avançar na leitura da história. Por seu prisma de estudos, aponta a realidade da criança em documentos, em telas que retrataram a vida das famílias, muitas vezes verificando que em geral os pequenos apareciam quase ao acaso nas imagens. Os pesquisadores e os documentos (oficiais ou não, como cartas familiares) nos fornecem significativos elementos sobre formas de presença das crianças na vida dos adultos. O mesmo autor nos informa que o termo infância decorre da palavra enfant, que é literalmente "não falante". Esta "fase" teria como indicador a idade de até sete anos de vida, quando devido à aquisição ainda frágil da linguagem e da condição biológica, por não ter a dentição completa, a criança não conseguiria se expressar com perfeição. Contudo, o historiador vai demarcar o lugar social de não ser ouvido. Evidentemente, estamos aqui realizando um sobrevoo ligeiro em relação à obra desse autor, fundamental para o debate sobre a infância.

A humanidade começou a efetivamente reconhecer a criança e o adolescente em suas particularidades há menos de dois séculos, cabendo aos adultos preservar seu pleno desenvolvimento por meio de cuidados privados e públicos. Nas obras de Ariès (1978) e de Rizzini e Pilloti (2009) temos um vasto leque para aprofundar as pesquisas sobre o atendimento à infância, que no caso brasileiro vai ter início com a catequização das crianças indígenas e dos filhos oriundos das relações entre homens europeus e mulheres indígenas e africanas. Essa é uma primeira marca sobre o domínio que permanece contra o desenvolvimento das crianças e adolescentes no Brasil. Não podemos negar o quanto essa trajetória vai demarcar decisivamente os rumos do trato a grande parcela da infância.

\section{Direitos humanos}

Para esta reflexão, buscaremos alguns elementos sobre o processo histórico da construção dos direitos humanos, que perpassa pelas revoluções burguesas. Estes processos históricos fundam a construção dos direitos civis e políticos cunhados pelo ideário liberal. Os principais autores nos quais nos apoiamos são Trindade (2003 e 2011a); Hobsbawm (2012 e 2008), Mészáros (2008) e Barroco (2010). 
Conforme estes e outros autores, os direitos humanos devem ser considerados enquanto conjunto de direitos econômicos, políticos, civis, sociais, culturais e ambientais, os quais são interdependentes e indivisíveis (ainda que limitado ao aspecto jurídico-formal). A trajetória de lutas e conquistas desses direitos é a referência histórica para compreendermos a busca da liberdade individual e da ruptura com a dependência interpessoal, traço marcante da sociedade feudal, que ainda mantinha resquícios naquele capitalismo nascente. Nesse sentido, o contrato entre "pessoas livres" seria o elemento-chave para o avanço da sociedade, que passaria a ter novos proprietários (por aquisição, e não apenas por herança). Contudo, para a elaboração de regras nessa nova forma de relação social, os burgueses liberais também precisavam consolidar direitos políticos — de votar e de ser votado para romper com o comando da nobreza e do clero. Era preciso construir uma nova classe política e também era necessária a defesa da laicidade. Era preciso construir uma nova classe política e também era necessária a defesa da laicidade. Neste sentido, retirando

[...] os direitos humanos do campo da transcendência, evidenciou-se sua inscrição na práxis sócio-histórica, [...] ao se apoiar em princípios e valores ético-políticos racionais, universais, dirigidos à liberdade e à justiça, a luta pelos direitos humanos incorporou conquistas que não pertencem exclusivamente à burguesia, pois são parte da riqueza humana produzida pelo gênero humano ao longo de seu desenvolvimento histórico, desde a Antiguidade. (Barroco, 2010, p. 55)

É nesse processo que se consolida a concepção de igualdade liberal, pautada na busca de uma pretensa e artificial equivalência jurídica (Trindade, 2011a). A história demonstra que esses direitos nasceram do desejo da burguesia de tomar para si privilégios restritos ao clero e à aristocracia. A possibilidade de pensar na igualdade social exigiu que a classe trabalhadora tomasse para si a bandeira de luta para que esses direitos fossem acessíveis a todos.

A Declaração dos Direitos Humanos de 1948 tem restrições, mas é importante registrar que

[...] foi resultado daquela correlação mundial de forças. Sem a pressão dos países do bloco soviético e sem a ascensão operária que se alastrava pelo mundo, seria inimaginável a inclusão dos direitos econômicos, sociais e culturais naquele documento, assim como seria inimaginável a inclusão do direito de autodeterminação dos povos sem as lutas de libertação nacional então em curso. (Trindade, 2011b) 
Portanto, a reivindicação era pelo direito de todos, mas provocada sempre pela classe que vive do trabalho. Esse fato não decorre de uma luta entre "bons e maus", não se tratando de um atributo de caráter, mas da real necessidade do ser social que se constrói em busca de respostas às suas questões diante da vida real:

Ora, a principal relação entre a história dos movimentos operários, que são um fenômeno bastante recente do ponto de vista histórico, e os direitos humanos reside no fato de que os movimentos operários geralmente são compostos de pessoas que são "subprivilegiadas", na palavras de R. D. Roosevelt, e que se preocupam com seus problemas. Isso quer dizer que eles se preocupam com pessoas que, segundo as definições de suas épocas, não têm os mesmos direitos, ou têm menos direitos do que outras pessoas ou outros grupos. Ora, as pessoas raramente exigem direitos, lutam por eles ou se preocupam com eles, a não ser que não os desfrutem suficientemente ou de nenhuma forma ou, caso desfrutem deles, a não ser que sintam que esses direitos não estão seguros. (Hobsbawm, 2008, p. 418)

Não pretendemos e nem temos condições de aprofundar a respeito das contradições desse processo histórico, sendo imprescindível nos apoiarmos nos autores citados para o devido estudo. Queremos neste breve artigo sinalizar que se os direitos humanos são uma construção social recente, também assim o é o reconhecimento da categoria criança e adolescente. ${ }^{1} \mathrm{~A}$ forma como eram pouco consideradas expressa parte do funcionamento da sociedade, em seus diversos processos. No caso da sociedade brasileira, é imprescindível pensarmos a infância marcada por uma violência de origem, que é a invasão, primeiramente de Portugal, às terras

1. Deve-se registrar que é possível observar em textos inclusive acadêmicos o uso de termos "as crianças e os adolescentes", e não necessariamente adotando-a como categoria "criança", "adolescente". Parece uma observação preciosista, mas entendemos ser crucial para maior aproximação com a realidade. Não se trata de seres sociais lançados a esmo na história: criança e adolescente são sujeitos em condição peculiar de desenvolvimento, inseridos em classe, com origem de classe, de diversas etnias e, no Brasil, de uma miscigenação étnico-cultural etc. Neste sentido, parece-nos importante que tenhamos sempre este cuidado: defendemos uma sociedade justa, igualitária, com direitos diferenciados para situações desiguais etc., para todas as crianças e adolescentes. Porém temos como premissa que há fatores determinantes que favorecem e/ ou prejudicam o pleno desenvolvimento desse sujeito. Não retiramos aqui as violências e as opressões às quais a criança e o adolescente da chamada classe média alta vive, com suas agendas superlotadas de compromissos que nem sempre lhes permite vivenciar seus desejos, sonhos e projetos. Há que se considerar, portanto, que as opressões da sociedade capitalista recaem brutalmente sobre a criança e o adolescente que têm origem na classe trabalhadora, mas também sobre aqueles oprimidos pelo ethos capitalista. Não se trata de "comparar" quem "padece" mais ou menos, mas fazer a defesa intransigente de uma sociedade realmente livre. 
deste território. Os estudos arqueológicos asseguram que os indígenas povoam este território há mais de 11 milhões de anos e que em 1500 havia cerca de 10 milhões de habitantes, dos quais cerca de 5,6 milhões na bacia amazônica. Posteriormente, sabemos das atrocidades que aconteceram sob o comando da Coroa portuguesa e da Igreja Católica, pois conforme o desenvolvimento mercantil avançou, foram sendo traçados novos "acordos", entre eles o escravismo de africanos e posteriormente o "fim" dessa barbárie. Estas questões não são de menos importância; são fundamentos da sociedade brasileira.

Afinal, como essa sociedade assistiu, sem grande repercussão, à recente morte por atropelamento de uma criança indígena de quatro anos, membro da família Guarani-Kaiowá do acampamento de Tekoha Apyka'i? Segundo o movimento de luta indígena, a criança é a quinta atropelada nos mesmos moldes de outras cinco pessoas, sendo que a primeira foi o seu avô, um líder religioso.

Não podemos cair na explicação maniqueísta-moralista para podermos avançar na análise e no enfrentamento das questões que assumem características complexas, mas que têm como fundamento a desigualdade social e a expropriação, necessidades para o desenvolvimento do capitalismo. Para quem importa a defesa dos direitos humanos?

Grupos especiais que esperam desfrutar de certas prerrogativas raramente se incomodam em erigir o que eles já possuem. [...]

Entretanto, o historiador não pode ficar satisfeito com a observação óbvia. Pois os movimentos operários europeus surgiram, e consequentemente começaram a influenciar a luta pelos direitos humanos se por sua definição, numa época em que o próprio conceito destes direitos estava passando por mudanças bastante profundas. (Hobsbawm, 2008, p. 419)

As lutas pelos direitos humanos, desencadeadas pela busca dos interesses de indivíduos e o movimento operário (pelos direitos do trabalhador, por uma vida digna e de forma mais ampla, pelo socialismo), contribuíram fundamentalmente para reinvindicações estruturantes visando mudanças econômicas e sociais. Hobsbawm (2008, p. 435) nos alerta ainda que a questão central não é o fato de indivíduos terem direitos econômicos e sociais, mas "políticas de cobrar impostos aos ricos para criar um fundo para pagamento aos pobres, aos desempregados e aos velhos, bem como para custear a educação popular. Sem essas políticas, estes direitos humanos são totalmente inúteis". 
Parece-nos que a questão-chave é a sequência do raciocínio desse historiador: "No desenvolvimento destas políticas, surgem inevitavelmente conflitos entre os direitos individuais e os sociais" (Idem).

Nesse contexto de conflito de interesses a concepção liberal dos direitos humanos se respalda no que Marx chamou de ilusão jurídica, não no sentido de ser mera ilusão, mas no do mascaramento de interesses em leis teoricamente "justas" e "neutras". Ao se referir a conflito, estão sendo anunciadas divergências que podem até ser pautas de "negociação", mas em uma sociedade desigual essa relação já está predeterminada.

Os direitos humanos liberais, ao retirar (ilusoriamente) as determinações históricas, consideram os sujeitos e seus direitos como abstrações, ficções e impõem o respeito "à sagrada propriedade privada" e aos indivíduos egoístas, protegidos por um leque de instituições criadas para tal finalidade. Como explica Marx (2007, p. 35): “A liberdade individual e esta aplicação sua constituem o fundamento da sociedade burguesa. Sociedade que faz com que todo homem encontre noutros homens não a realização de sua liberdade, pelo contrário, a limitação desta."

\section{Criança e adolescente e o desafio de se efetivar direitos humanos}

A literatura especializada tem possibilitado maior divulgação da realidade vivida pela criança e pelo adolescente. Se por um lado isso pode ser um indicador importante sobre o reconhecimento das particularidades dessa fase de desenvolvimento em toda sua complexidade, por outro, devido à cultura existente, ainda termos a passividade da sociedade em relação às violações.

As discussões sobre a violação dos direitos da criança muitas vezes deixam de articular as determinações macrossocietárias. Se a literatura científica vem avançando nessa crítica, a mídia mantém a postura de enfocar os "pobres abandonados" e os "infratores", colocando-os na mesma perspectiva justificadora das violações e mantendo a lógica menorista do Código de Menores. Muitas legislações foram construídas com foco na criança abandonada. Maria Regina Fay Azambuja ${ }^{2}$ explica que

2. Disponível em: <http://www.mp.rs.gov.br/infancia/doutrina/id615.htm>. Acesso em: 29 maio 2013. 
A Declaração de Genebra, em 1924, afirmou "a necessidade de proclamar à criança uma proteção especial", abrindo caminho para conquistas importantes que foram galgadas nas décadas seguintes. Em 1948, as Nações Unidas proclamaram o direito a cuidados e à assistência especial à infância, através da Declaração Universal dos Direitos Humanos, considerada a maior prova histórica do consensus omnium gentifum sobre um determinado sistema de valores. Os Pactos Internacionais de Direitos Humanos, indiscutivelmente, proporcionaram a mudança de paradigmas experimentada no final da década de oitenta e início dos anos noventa na área da proteção da infância.

A sociedade brasileira convive com as marcas da ditadura civil-militar de 1964, e nos processos de lutas e resistências avançou para a "transição democrática", mas, de acordo com Netto (2004), mantém, com particularidades, a histórica "refuncionalização" das "formas socioeconômicas" existentes na formação brasileira.

Salientamos, com essas rápidas notas, que é fundamental romper com o discurso de que o debate sobre a família e a infância sejam voltados para conservadorismo ou que sejam acessórias. Para desconstruir esses discursos aparentemente críticos nos é exigido rigor da análise histórica. Afinal, as lutas sociais expressam as contradições profundas vividas pelo ser social que se constrói nessas relações históricas. É inegável que, diante da barbárie que afeta segmentos como a população infantojuvenil, há uma tendência de a luta se expressar mais em buscar "conservar" os direitos minimamente consensuais (à vida, à sobrevivência, à alimentação). Tão grave é a realidade de crianças diante dos conflitos gerados pelo capitalismo vigente, que se apresentam os recuos com uma aparente agenda limitada de reivindicações. É esse contexto de barbárie que deve nos alarmar, sendo crucial a adoção de estratégias que se dirijam a outro projeto de sociedade.

Nesse sentido, é importante registrar que a United Nations Children's Fund (Unicef) lançou o relatório A situação mundial da infância em 2012, trazendo elementos sobre os avanços e desafios com relação à criança num mundo cada vez mais urbano.

As dificuldades enfrentadas pelas crianças em comunidades pobres frequentemente são obscurecidas - e portanto, perpetuadas - pelas médias estatísticas que servem de base para decisões sobre alocação de recursos. Uma vez que médias consideram todos os dados em conjunto, a pobreza de alguns é mascarada pela riqueza de outros. Como consequência, crianças que já são menos favorecidas ficam privadas de serviços essenciais. (p. iv) 
Esta é uma questão-chave quanto à realização dos direitos humanos: atender individual e coletivamente os diferentes segmentos, por meio de serviços que garantam a sua realização.

Não tratamos esta questão como algo simples ou mera carta de intenções ou conciliação de interesses, posto que no capitalismo são antagônicos. Trindade traz os elementos históricos que provam que a cada risco de a burguesia ter seu poder abalado, a reação sempre foi sangrenta. No Brasil de 2013 as mortes decorrentes desses conflitos têm sido matéria cotidiana, seja nas ocupações militares nas favelas, no confronto no direito à terra, no assassinato de jovens negros da periferia (que autores vão definir como genocídio da juventude negra), no espancamento dos estudantes e trabalhadores nas suas (nossas) manifestações por direitos etc.

Outro importante estudo que demonstra a imperiosa atenção que devemos ter em relação à infância é o $5^{\circ}$ Relatório Nacional sobre os Direitos Humanos no Brasil (2001-2010) publicado pelo Núcleo de Estudos da Violência da Universidade de São Paulo (NEV-USP). Na apresentação o coordenador do NEV, dr. Sérgio Adorno, explicita que

Este relatório reafirma uma vez mais o imperativo de superar o estágio de "desconfiança", que domina o que se poderia chamar de "opinião pública informada", segundo a qual persistem sérios problemas de violações de direitos humanos no Brasil em grande escala, ocorrendo diariamente em todo o país. Embora essa desconfiança ainda seja sustentada pelos fatos cotidianos, impõe-se ultrapassar esse estágio na direção de uma fase de mapeamento das situações e elaboração de políticas públicas informadas e eficientes. É evidente que gerar informações sobre violações de direitos humanos são é uma tarefa simples, sobretudo para os governos. Assumir que essas violações ocorrem cotidianamente e que envolvem a constante ameaça à vida e à integridade física das pessoas, muitas vezes causadas por agentes públicos, parece ainda ser visto por muitos governantes como politicamente inconveniente, até porque parte das graves violações de direitos humanos tem a ver com a omissão dos Estados na proteção e promoção de direitos humanos. (NEV-USP, 2012, p. 7)

Essa perspectiva de análise perpassa o relatório, que anuncia que nos dois últimos relatórios (2006 e 2010) houve ênfase na abordagem dos direitos econômicos, sociais e culturais. Em nossa leitura, observamos o grande volume de publicações, sejam oficiais, da academia especificamente ou dos movimentos sociais e outras organizações dos trabalhadores (associações populares, sindicatos etc.) que 
têm se debruçado seriamente sobre o tema violação dos direitos humanos no Brasil. Este é um indicador importante que expressa a provocação da realidade.

Os desafios colocados para os trabalhadores são imensos e nos parecem exigir uma apropriação urgente e profunda sobre a não efetivação de direitos legalmente constituídos e que exigem políticas públicas estatais para se materializar. O chamado Estado democrático de direito vem mobilizando sua "funcionalidade" impulsionada por interesses privados, como autores de diversas perspectivas têm refletido suas produções. Atualmente vivemos o avanço da política neoliberal, com as modalidades de privatização de serviços e/ou desenvolvimento das "parcerias público-privadas" em que em geral o Estado transfere recursos públicos (estrutura, equipamento e orçamento) para a área privada. Debatendo a política social na atual conjuntura, Sales (2006, p. 210-211) afirma que

É mister, portanto, compreender a situação da infância e adolescência como uma expressão da questão social, logo em conexão com os demais desafios sociais do país, e o papel do conjunto de atores sociais vinculados à luta pela garantia dos seus direitos, assegurando-lhe a centralidade e visibilidade devidas. Pois como diria Mendes, “o que está em jogo, em última instância, é o tema da democracia e da cidadania [...]. Ninguém que fale da infância, do ponto de vista do paradigma da proteção integral, deixa de falar em democracia. Mas são poucos aqueles que, falando de democracia, falam de infância".

$\mathrm{O}$ enfrentamento da violência contra a criança e o adolescente expressa a defesa de diferentes projetos de sociedade, ainda que isso não se seja declarado. E esta é uma questão muito cara aos processos políticos: qual a direção social dessas lutas, suas estratégias, seus balanços críticos? Exige-se uma avaliação permanente do avanço político face às novas roupagens colocadas na "velha" questão social.

Expressão destas violências são apontadas no relatório do NEV, anteriormente citado: "Segundo a Organização Mundial da Saúde (OMS), 53.000 crianças entre 0 e 18 anos morreram vítimas de homicídio em 2002. Cerca de 150 milhões de meninas e mais de 70 milhões de meninos foram submetidos a abusos sexuais de toda ordem" (NEV-USP, 2012, p. 222).

Poderíamos abrandar nossas "consciências" de cidadãos da sétima economia mundial imaginando que o Brasil não faz parte dessa realidade. Contudo, o país comete muitas violações dessa estatística, sendo o quarto país que mais comete homicídios de suas crianças e adolescentes. Dados oficiais informam ainda que em 
2009, no Brasil, entre as crianças de cinco a dezessete anos, 9,8\% deles, ou seja, 4.250.401, encontravam-se exercendo "trabalho", sendo que o trabalho infantil é vedado legalmente, sendo, que desse número, 1.380.489 tinham idades entre cinco e catorze anos.

O $5^{\circ}$ Relatório do NEV traz uma importante abordagem sobre adolescência e violência, criticando a inexistência de pesquisas abrangentes sobre as medidas socioeducativas em meio aberto, porém enfatizando debate da privação de liberdade dos adolescentes. Esta questão soma-se a outros elementos que gravitam em torno do agravamento penal na sociedade. Notadamente, o discurso distorce a realidade, mobilizando a opinião pública a partir de fatos de grande impacto e comoção social. Contudo, tais fatos são deliberadamente escolhidos. Os dados sobre o perfil do adolescente que se encontra cumprindo medida de internação ou mesmo do jovem encarcerado explicita que os sujeitos encarcerados são aqueles pertencentes à camada mais violada em seus direitos fundamentais. No estado de São Paulo, de 2010 a 2013 houve um aumento de 32,5\% de aumento de adolescentes cumprindo medida socioeducativa de internação. O Conselho Nacional de Justiça ${ }^{3}$ realizou um levantamento envolvendo 340 unidades de internação no território brasileiro mapeando as violações de direitos dos adolescentes internados. Há reivindicações para a efetivação da resolução do CNJ para a contratação de equipes interprofissionais nas Vara da Infância e da Juventude. A resolução foi um dos desdobramentos da pesquisa do Ipea, que apontou a existência de 80 mil crianças vivendo em instituições de acolhimento sem que estas cumprissem ao menos disposições legais (para não dizer das pedagógicas etc.). Segundo dados do Ministério da Justiça, por meio do Disque 100, mais de 128 mil crianças e adolescentes foram vítimas de maus-tratos e agressões. Deste total, $68 \%$ sofreram negligência; $49,20 \%$, violência psicológica; $46,70 \%$, violência física; $29,20 \%$, violência sexual; e $8,60 \%$, exploração do trabalho infantil. Atualmente, segundo dados do CNJ, 36.929 vivem em instituições de acolhimento.

A sociedade atuou de forma decisiva para incluir o artigo 227 na Constituição, bem como na elaboração e aprovação do ECA. Marcada pela luta pela redemocratização, entendemos que o Estatuto é um marco ético-político. ${ }^{4}$ Não pode ser

3. Conheça e pesquise no portal do Conselho Nacional de Justiça, em <www.cnj.jus.br>. A fiscalização da aplicação das medidas socioeducativas é realizada também pelo Programa Justiça ao Jovem, do CNJ, e pelos demais atores do Sistema de Garantia de Direitos Humanos da Criança e do Adolescente.

4. Expressão que definimos na nossa dissertação de mestrado (2006). 
tomado como $o$ instrumento central, mas como uma referência que somente foi possível conquistar num dado contexto ideopolítico em que foi disputado e aprovado. Ocorreram perdas nessas disputas, e o seu não cumprimento revela o quanto a sociedade brasileira não rompeu com a cultura menorista, autoritária, centralizadora, patriarcal-machista-patrimonialista. $\mathrm{O}$ reconhecimento da criança como sujeito de direitos exige, efetivamente, intensa mudança cultural. Neste sentido, apesar de sabermos dos limites dos instrumentos legais, é importante registrar a relevância da Resolução n. 113, de 19 de abril de 2006, publicada pelo Conselho Nacional dos Direitos da Criança e do Adolescente (Conanda). Nela se explicita a definição do chamado "Sistema de Garantia de Direitos":

Art. $1^{\circ} \mathrm{O}$ Sistema de Garantia dos Direitos da Criança e do Adolescente constitui-se na articulação e integração das instâncias públicas governamentais e da sociedade civil, na aplicação de instrumentos normativos e no funcionamento dos mecanismos de promoção, defesa e controle para a efetivação dos direitos humanos da criança e do adolescente, nos níveis federal, estadual, distrital e municipal.

$\S 1^{\circ}$ Esse Sistema articular-se-á com todos os sistemas nacionais de operacionalização de políticas públicas, especialmente nas áreas da saúde, educação, assistência social, trabalho, segurança pública, planejamento, orçamentária, relações exteriores e promoção da igualdade e valorização da diversidade. (Conanda, 2006)

Esta Resolução utiliza, não por acaso, o termo "direitos humanos" e em seu teor trata inclusive da eleição dos membros da sociedade civil, situação esta debatida intensamente com o protagonismo do Fórum Estadual dos Direitos da Criança e do Adolescentes de São Paulo. As Resoluções ns. 105 e 106 do Conanda estabeleceram normas para a criação e o funcionamento desses Conselhos, inclusive que a eleição dos representantes da sociedade civil seja realizada por meio de pleito "em fórum próprio", ou seja, sem a condução pelo poder governamental. Não cabe aqui debater as relevantes questões sobre as sociedades civil e política, bem como a avaliação do (mal) uso que se tem feito desses mecanismos de controle social. Porém, deve-se verificar a existência de um conjunto de instrumentos normativos que ainda são negligenciados.

A exemplo dessas problematizações, temos as Regras de Bangcoc, ${ }^{5}$ estabelecida pela Resolução n. 2.010/16, de 22 de julho de 2010, e o Conselho Econômico

5. Veja a tradução não oficial realizada pela Pastoral Carcerária disponível em: <www.carceraria.org. br $>$ e outros documentos importantes em: <www.adital.com.br>. Acesso em: 20 jan. 2013. 
e Social, que recomendou à Assembleia Geral a adoção das regras das Nações Unidas para o tratamento de mulheres presas e medidas não privativas de liberdade para mulheres infratoras. A resolução foi aprovada na $65^{\mathrm{a}}$ Assembleia da Organização das Nações Unidas, enfatizando a importância do reconhecimento das particularidades do gênero feminino, visando, dentre diversas dimensões da questão, "assegurar que a mulher infratora fosse tratada justa e igualmente durante a prisão, processo, sentença e encarceramento, com atenção especial dedicada aos problemas específicos enfrentados pelas mulheres infratoras, tais como gravidez e cuidados com os filhos".

Segundo a legislação brasileira, as unidades prisionais devem ter berçários (art. 83, $\S 2^{\circ}$ da Lei n. 7.210/1984, com as alterações da Lei n. 11.942/2009) e creches para filhos entre seis meses e sete anos (art. 89 da Lei n. 7.210/1984, com as alterações da Lei n. 11.942/2009). No Código de Processo Penal, em relação à prisão domiciliar (perspectiva apontada também nas Regras de Tóquio sobre as alternativas à prisão), temos que:

Art. 318. Poderá o juiz substituir a prisão preventiva pela domiciliar quando o agente for: (Redação dada pela Lei n. 12.403, de 2011).

$[\ldots]$

III - imprescindível aos cuidados especiais de pessoa menor de 6 (seis) anos de idade ou com deficiência; (Incluído pela Lei n. 12.403, de 2011).

IV - gestante a partir do $7^{\circ}$ (sétimo) mês de gravidez ou sendo esta de alto risco. (Incluído pela Lei n. 12.403, de 2011).

A Lei de Execução Penal define que caso a unidade não garanta condições para a amamentação e/ou convívio entra a genitora e a criança, deverá ser determinada a prisão domiciliar.

Portanto, as legislações estabelecem direitos que não são respeitados e geram outras violações. Ainda vivenciamos um discurso machista que está presente inclusive na defesa de que a criança deve permanecer com a genitora somente no período de amamentação, ainda na perspectiva higienista e de controle do corpo da mulher. Contudo, o direito à amamentação sequer é respeitado. São contradições que perpassam pela lógica punitiva-conservadora.

O texto legal acima pode ser tensionado ao se afirmar os direitos fundamentais da criança e do adolescente, valendo-se da defesa das penas alternativas para reduzir os danos causados ao grupo familiar. Contudo, há pouca política propria- 
mente dita nas políticas sociais (a segurança pública é uma delas). Vemos a baixa institucionalidade no controle social e o discurso do senso comum sobre a falência do Estado.

A prisão domiciliar que deveria ser determinada em substituição à prisão preventiva quando o agente for "imprescindível aos cuidados especiais", conforme nossos argumentos no percurso desta reflexão, devem ser complementados com o princípio do superior interesse da criança e do adolescente, que são sujeitos de direitos e pessoas em condições peculiares de desenvolvimento. Portanto, entendemos que a substituição da prisão preventiva pela domiciliar deva ser aplicada em todas as condições possíveis, independentemente da idade dos filhos. E abre-se a imperiosa necessidade de discutirmos as figuras parentais e os vinculos protetivos - e não necessariamente a mãe biológica. A ciência demonstrou a relevância da presença materna na primeira infância, mas não se restringiu a ela. Estas breves pontuações sobre o encarceramento de mulheres abrem muitas frentes, não para aperfeiçoar o cárcere, o que consideramos ser um engodo, mas para problematizar a função do sistema penal-punitivo numa sociedade opressora que precisa construir a todo momento novos depositários e "bodes expiatórios" para mascarar suas contradições.

\section{Considerações para debates}

Enfrentar a questão da violação de direitos humanos da criança e do adolescente requer, nesse sentido, uma profunda e sistemática articulação das análises sobre a sociedade contemporânea, as perspectivas ideopolíticas que fundamentam as decisões adotadas na elaboração e na execução das políticas públicas e o confronto com a real mudança na vida da população.

A história também nos elucida os processos provocados pelos trabalhadores e, aproximando-as para a interpretação da conjuntura, podem favorecer nossa reflexão crítica:

Foi a herança histórica dos movimentos socialistas e operários, da tradição de racionalismo esclarecido do século VII, que manteve esses instintos [xenofobia, racismo, machismo, antissemitismo e inferiorização das mulheres] sob controle. Sem ela, eles não teriam nem tentado, nem conseguido, tornar-se foco para os direitos iguais $\mathrm{e}$ 
universais e para a emancipação universal do homem. Pois nem todos os movimentos dos que exigiam direitos tinham esta intenção ou esta capacidade. [...]

Será que tudo isso ainda é verdadeiro? Provavelmente, só até um certo limite. A linguagem dos direitos humanos ainda é falada, mas num cenário diferente daquele do século XIX e do início do século XX. A luta por direitos humanos ainda é vista, em diversos países, como parte de um programa geral pelo progresso da humanidade, em nível individual e coletivo, na direção de um futuro melhor e mais genuíno para o homem. (2000, p. 438)

O texto anterior, escrito originalmente em 1982, nos instiga a afirmar, como Trindade (2011) que estamos vivendo um recuo imenso na agenda de direitos humanos liberais! Estamos lutando pelo direito civil de participar criticamente (com a reação violenta do Estado em defesa dos interesses privados), em que está descartado o direito ao conflito de posições, que é base da democracia. Estamos exigindo o fim da tortura! O Brasil engatinha com a Comissão da Verdade quando os demais países já avançaram imensamente nesse processo. E recentemente volta-se a afirmar que a solução de todos os males brasileiros é a redução da maioridade penal e que há "uma nova forma de fazer política" por meio das mobilizações momentâneas/instantâneas (flash mob) ${ }^{6}$ para "expressar" as discordâncias e desaparecer também com a mesma rapidez, banalizando (desvalorizando) a política e as formas tradicionais de luta (movimentos sociais, sindicatos e partidos).

É importante nos apropriarmos das conquistas normativo-legais sem nos iludirmos quanto aos fundamentos ontológicos do direito na lógica da sociedade capitalista. São conquistas, mas conforme explicita Barroco, referindo-se às Declarações de Direitos Humanos:

[...] podem ser considerados como uma medida para evidenciar o grau de humanização-desumanização do ser social, e, uma forma de contribuição, ainda que limitada, para a sua reprodução em patamares menos desumanizantes. [...]

Portanto, compreender essa contraditoriedade significa saber que a defesa dos Direitos Humanos pode servir, por um lado, à apologia do capitalismo, contribuindo para a legitimação ideológica de interesses de dominação e para o ocultamento das formas de degradação da vida humana. Mas, se, ao mesmo tempo, o reconhecimento univer-

6. Essas manifestações vêm gerando o interesse de pesquisadores, tema que não temos propriedade para debater neste artigo. Contudo, é um fato relevante para entendermos principalmente a forma particular pela qual a juventude (adolescentes e jovens adultos) vem buscando se "expressar". 
sal da totalidade dos Direitos Humanos e o seu alargamento é um produto concreto do conjunto das lutas sociais, embora limitado, ele representa uma estratégia de resistência, no universo da luta de classes, no interior das lutas mais gerais dos trabalhadores e dos movimentos populares. (2010, grifos no original)

A presença da pauta dos direitos humanos não apenas na agenda dos órgãos governamentais, internacionais, da mídia, dos trabalhadores, da academia e dos movimentos populares, representa a disputa que está colocada e, principalmente, o retrocesso nos patamares mínimos de convívio. Desenvolver nosso conhecimento sobre as questões macrossocietárias e da sociabilidade no presente tem como norte comum a proteção de toda a vida planetária. As propostas de conciliação e de aperfeiçoamento do sistema em vigor são desnudadas ao confrontarmos a inexistência de mudanças efetivas na vida da maioria da população. O Brasil dessa primeira década do novo milênio teve êxito em garantir maior acúmulo de riquezas, aprofundando-se a distância entre os mais ricos e os mais pobres. Não se trata de não valorizar as políticas sociais que minimizam o sofrimento humano, mas de reconhecer seus limites.

A luta social propriamente dita tem como fundamento o processo de construção de uma lógica de sociedade, mesmo quando não se tem consciência disso. Nesse sentido, defender os direitos humanos da criança e do adolescente é uma estratégia que entendemos necessária para a perspectiva revolucionária e emancipatória, exigindo que possamos construir processos de sociabilidade que disputem o ethos dominante burguês, mas com direção e projeto político.

\section{Recebido em 11/6/2013 - Aprovado em 17/6/2013}

\section{Referências bibliográficas}

ARIÈS, Philippe. História social da criança e da família. Rio de Janeiro: LTC, 1981.

AZAMBUJA, M. R. A criança, o adolescente: aspectos históricos. Disponível em: <http:// www.mp.rs.gov.br/infancia/doutrina/id615.htm>. Acesso em: 29 maio 2013.

BARROCO, M. L. Ética e direitos humanos. In: COLÓQUIO ÉTICA E DIREITOS HUMANOS DO ENCONTRO NACIONAL DE PESQUISADORES EM SERVIÇO SOCIAL. Rio de Janeiro, 2010. 
BRASIL. Lei de Execução Penal. Lei n. 7.210/84, com as alterações da Lei n. 11.942/2009.

Estatuto dos Direitos da Criança e do Adolescente. Lei n. 8.069/90, de 13 de julho de 1990.

CONANDA. Resolução n. 113, de 19 de abril de 2006.

FUZIWARA, A. S. Contribuição do assistente social para a área da justiça da infância e da juventude: o laudo social e a aplicação da lei — encontros e desencontros. Dissertação (Mestrado) - Pontifícia Universidade Católica, Faculdade de Serviço Social, São Paulo, 2006.

HOBSBAWM, E. Mundos do trabalho: novos estudos sobre história operária. 5. ed. rev. São Paulo: Paz e Terra, 2008.

A era dos extremos. O breve século XX: 1914-1991. 2. ed. 48. reimpr. São Paulo: Companhia das Letras, 2012.

MARX, K. A questão judaica. 2. ed. São Paulo: Moraes, 1991.

MÉSZÁROS, I. Filosofia, ideologia e ciência social. São Paulo: Boitempo, 2008.

NETTO, J. P. Ditadura e serviço social: uma análise do serviço social no Brasil pós-64. 7. ed. São Paulo: Cortez, 2004.

NÚCLEO DE ESTUDOS DA VIOLÊNCIA DA UNIVERSIDADE DE SÃO PAULO (NEV-USP). $5^{\circ}$ Relatório Nacional sobre os Direitos Humanos no Brasil (2001-2010). São Paulo, 2012.

ORGANIZAÇÃO DAS NAÇÕES UNIDAS (ONU). Resolução n. 2.010/16, de 22 de julho de 2010 .

RIZZINI, I.; PILLOTI, F. A arte de governar crianças: a história das políticas sociais, da legislação e da assistência à infância no Brasil. 2. ed. rev. São Paulo: Cortez, 2009.

SALES, M. A. Política de direitos da criança e do adolescente: entre o litígio e a tentação do consenso. In: SALES, Mione A.; MATOS, C.; LEAL, Maria C. Política social, família e juventude: uma questão de direitos. 2. ed. São Paulo/Rio de Janeiro: Cortez/UFRJ, 2006.

TRINDADE, J. D. L. História social dos direitos humanos. São Paulo: Peirópolis, 2003. Os direitos humanos na perspectiva de Marx e Engels: emancipação política e emancipação humana. São Paulo: Alfa-Ômega, 2011a.

Os direitos humanos e a síndrome de Poliana, 2011b. [Arquivo digitalizado.]

UNICEF. A situação mundial da Infância - 2012: crianças em um mundo urbano. Nova York, 2012. Disponível em: <www.unicef.org/sowc2012>. Acesso em: 19 abr. 2013. 